\title{
Teorías democráticas hoy : ¿cuál de ellas garantiza la igualdad, la libertad y la virtud?
}

Eduardo Hernando Nieto

\section{Introducción}

Si hay una palabra en el alfabeto polítice que ha sido utilizada por todos los espectros ideológicos en los últimos años, esa es la palabra democracia y nos transporta inmediatamente a un reino perfecto en el cual podría existir, por ejemplo, el consumidor ideal que materializara de modo inmediato todos sus deseos como si fuese el poseedor de la lámpara de Aladino $^{1}$ o también el hombre solidario y altruista que quiera dar de su bolsillo y ayudar gratuitamente al indigente o apoyar a sı mismo camarada o compañero de clase raza o género. ${ }^{2}$

Sin embargo, así como hay palabras que quedan marcadas por el idealismo, las hay también aquellas que evocan calamidades, como podrían ser el populismo o el fascismo y con las cuales ciertamente nadie quisiera ser comprometido. De hecho, es evidente que ningún partido o ningún Estado quisiera llevar la etiqueta de fascista o populista, mas todos desearían conocerse y proclamarse como demócratas.

Pero tantas veces se repite la palabra democracia que parecería ser como un pariente cercano que quizá hasta conviva en nuestra casa, y se

1 Referencia necesaria al gran escritor y ensayista alemán Ernst Jünger, quien atisbó que el gran problema del hombre moderno era precisamente el de convertirse gracias a la técnica, en dueño de un poder terrible que al final lo someterá y controlará. En esta misma perspectiva Oswald Spengler ya mencionaba la naturaleza Faústica del sujeto de poder. Cfr Ernst Jünger, El problema de Aladino, Madrid, Cátedra, 1987, Oswald Spengler, La Decadencia de Occidente Madrid, Espasa - Calpe, 1958.

2 Pensemos en el caso del marxismo por ejemplo y de las corrientes humanistas que de él derivaron. 
piense entonces que por reunir estas condiciones se da por hecho de que todos conocemos su identidad y también sus cualidades y características. Empero, así como se dice que la saturación de medios de comunicación y de información al final nos llevan a la incomunicación y al desconcierto ${ }^{3}$, este mismo efecto estaría afectando también a la comprensión del propio concepto de democracia y la manera de aproxiinarnos a su significado.

En este sentido, la idea de este artículo es buscar aclarar -en primer lugar- las características y peculiaridades de este huésped que todos se jactan de albergar y ver inmediatamente que no se trata de un personaje fácil de clasificar y definir. Por el contrario, nos encontraremos ante un término que se ha moldeado y que continua haciéndolo de acuerdo a las circunstancias y que esto ha dado como resultado al menos la vigencia de cuatro definiciones del mismo, las cuales no necesariamente buscarán semejantes objetivos y que tampoco serían necesariamente compatibles entre sí.

Un segundo propósito de este trabajo estará dirigido al análisis de la relación entre la libertad y la igualdad en todas las definiciones modernas conocidas de la democracia. Esto podrá derivar entonces, en definiciones sustantivas y generales (léase idealistas o prescriptivas) que privilegiarán por sobre todas las cosas la igualdad, mientras que versiones con concepciones del bien más ligeras y menos ambiciosas (léase más pragmáticas y descriptivas) procurarán asegurar por todos los medios la libertad de elección y la autonomía.

Finalmente, es nuestro interés el de derivar en una teoría democrática que algunos podrían denominar republicana, y que se originaría de fórmulas políticas clásicas más cercanas a la tradición originaria del modelo republicano que a las tesis renacentistas. Tal teoría colocaría su acento en la virtud de la ciudadanía (sustentada $\in \mathrm{n}$ las obligaciones y no en los derechos) y se opondrá a las visiones mecanicistas y/o contractualistas derivadas de las tesis democráticas modernas, poniendo en su lugar una perspectiva orgánica y teleológica capaz de sintetizar lo prescriptivo con lo descriptivo (esto es, lo ideal con lo real) merced a privilegiar la virtud por encima de la libertad y de la igualdad.

3 John Keane, "Lo público en la era de la abundancia» en Ciudadanos en la Sociedad de la Información, editado por Miguel Giusti y María Isabel Merino, Lima, Fondo Editorial de la PUC, 1999, pp.23-39. 


\section{Primera teoría: la democracia sustantiva}

La teoría democrática que más se aproxima a las fórmulas políticas clásicas ${ }^{4}$ es, sin duda, la llamada democracia sustantiva pues busca por todos los medios asegurar la igualdad entre todos los miembros de la colectividad. Una identidad de este tipo podía entonces agrupar a muchas personas que se unían en aras de vivir juntos y de autogobernarse, diferenciándose de otros grupos antagónicos. Se dice entonces, que lo que tipifica a este concepto es la identidad y que hace así del pueblo el detentador de una suerte de poder constituyente; ${ }^{5} \sin$ embargo, es menester indicar que este concepto de democracia (igualdad entre gobernante y gobernados) tiene que estar centrado en un pueblo específico pues como también mencionaba el teórico político y constitucionalista alemán Carl Schmitt «la igualdad de todo el que tenga figura humana no puede ofrecer fundamento ni a un Estado, ni a una forma política, ni a una forma de gobierno. De ella no pueden obtenerse distinciones y límites; con ella no pueden construirse instituciones especialmente estructuradas, y sólo puede comportar la disolución y abolición de distinciones e instituciones que ya no tengan fuerza en sí mismas». ${ }^{6}$ En consecuencia, la democracia sustantiva podía ser considerada como un concepto político pues se basaba en la distinción y proponía así una igualdad entre los que son iguales.

En realidad, a quien se le considera el forjador de esta fórmula democrática es al filósofo francés del siglo XVIII Jean Jacques Rousseau, quien en su famoso Contrato Social, decía que el pacto social (que daba nacimiento a la comunidad política) podía resumirse en "la alienación total de cada asociado con sus innegables derechos a toda la comunidad. Pues primeramente, dándose por completo cada uno de

4 Entendemos por fórmulas políticas clásicas a aquellas que según las conocidas teorías del sociólogo alemán Ferdinand Tönnies, representan una "Gemeinschaft» o comunidad que tiene características naturales y holistas. También pensamos en términos schmittianos, vale decir, siguiendo los argumentos planteados por el teórico político alemán que identifica a lo político en función a la diferencia entre amigos y enemigos, por ende, un grupo político es en síntesis «una comunidad de amigos". Cf. Ferdinand Tönnies, Community and Association, London, Routledge and Kegan Paul, 1958, Carl Schmitt, El Concepto de lo Político, Madrid, Alianza, 1991.

5 Carl Schmitt, Teoría de la Constitución, Madrid, Alianza, 1982, p.221

$6 \quad$ Ibid. p. 224 
los asociados, la condición es igual para todos; siendo igual, ninguno tiene interés en hacerla gravosa para los demás [...]. Si se descarta, pues, del pacto social lo que no constituye su esencia, encontraremos que el mismo se reduce a los términos siguientes : cada cual pone en común su persona y su poder bajo la suprema dirección de la voluntad general, y cada miembro es considerado como parte indivisible del todon.?

Pero, este acuerdo evidentemente era fruto de un artificio, es decir se trataba de generar una sociedad bien ordenada que superase en realidad el primer artificio (en especial la agricultura, el comercio y la metalurgia) que fue inconsciente y que generó la corrupción del estado de naturaleza. Este segundo artificio era entonces -y a diferencia del anterior- en su totalidad racional y voluntario y por eso podía producir un orden político justo e igualitario; ${ }^{8}$ el cuerpo soberano sería así toda la comunidad y esto significaría que toda ella sería una sola voluntad, y los sujetos no se obligarían a obedecer a una mayoría o a una minoría sino a toda la comunidad.?

Empero, el hecho de incorporar a la voluntad, sea individual o sea colectiva, implicaba ya una forma de gobierno moderno en todo el sentido de la palabra, pues aquí estábamos ante un fenómeno de poder que ciertamente no era lo común dentro de cualquier modelo político tradicional como, podía ser el caso, por ejemplo, de las polis griegas. ${ }^{10}$ Asimismo, se rodeaba a esta decisión de la voluntad general de un hálito de certeza absoluta pues la voluntad general era infalible y siempre correcta ${ }^{11}$, de este modo se aseguraba también la libertad y seguridad de los ciudadanos al identificarse la voluntad del soberano con lo bueno y el bien para cada uno de los participantes en el contrato.

Ahora bien, el contrato social siendo, como se dijo, un artefacto que debía servir para satisfacer las necesidades de los hombres, podría

7 Jean Jacques Rousseau, El Contrato Social, Libro I, Cap.VI, Madrid, Sarpe, 1985.

8 Maurizio Viroli, Jean Jacques Rousseau and the "well-ordered society", Cambridge, Cambridge University Press, 1988, pp. 37 - 38.

9 Arthur Melzer, The Natural Goodness of Man, on the system of Rousseau's thought, Chicago, Chicago University Press, 1990, p.153.

10 Cfr. Josiah Ober, The Athenian Revolution, essays on ancient greek democracy and political theory, Princeton, New Jersey, Princeton University Press, 1996; M.I Finley, Politics in the Ancient World, Cambridge, Cambridge University Press, 1983.

11 Arthur Melzer, Ibid., pp.155 - 156. 
parecer en principio una teoría política real y no moral o metafísica, sin embargo, inmediatamente saltaba a la vista la imposibilidad de realizar la igualdad que ella pretendía ${ }^{12}$ y de hecho es de aquí que se empezará a asociar a esta perspectiva con el idealismo que distorsionaría el talante político de la democracia sustantiva ${ }^{13}$. Así pues, cuando esta perspectiva se fusione con las teorías filosóficas de autores como Hegel o Marx se obtuvo un marco teórico algo distinto:

«En la visión más radical de esta doctrina clásica (que nos conduce de Rousseau a Babeuf y de allí a Marx, el sovietismo de Lenin, los consejos de trabajadores de Rosa Luxemburgo, el "auto - gobierno de los productores" en Gramsci y culmina idealmente en la teoría marxista de la desintegración del Estado), la amalgama de las nociones de democracia, voluntad general y bien común está completa.." ${ }^{14}$

Ciertamente, el poder democrático se identificaba con una expresión directa y constante de la voluntad del pueblo, lo que hacía a esta

12 Artlur Melzer señala sobre este respecto que Rousseau entiende que la voluntad general no es metafísica y en el fondo sabe que su "voluntad general" debe de ser representada por unos pocos que se encuentran en un nivel superior que el resto. Esto demostraría a las claras que Rousseau más que igualitarista fue un creyente fiel en la desigualdad humana.

«El desigualitarismo de Rousseau tiende a oscurecerse por diversos factores. Su fascinadora descripción del estado de naturaleza donde los hombres son iguales a causa de la falta de desarrollo de sus facultades ha distraído la atención de su alegato en el sentido de que devienen naturalmente desiguales cuando desarrollan sus facultades. También, la brillantez y fuerza de sus ataques sobre la injusta desigualdad ha cegado a los lectores de su reconocimiento de que existe una injusta y genuina desigualdad. Finalmente, su nuevo espíritu humanitario y su identificación con la causa de la gente, que ciertamente constituye un importante paso en aras de la igualdad, ha sido erróneamente visto como un repudio hacia cualquier forma de desigualdad". Arthur Melzer, Ibid., p.156.

13 Esta diferencia entre las tesis sustantivas de Rousseau y las democracias sustantivas que se perfilarán en el pensamiento hegeliano y marxiano ha sido destacado por el teórico político y sociólogo británico David Held, quien inclusive los coloca dentro de distintas tipologías, pues para él Rousseau entraría dentro de una Democracia Evolucionista o Desarrollista mientras Hegel y Marx irían en el cuadro de las Democracias Directas. El primer modelo sería más bien reduccionista en el sentido de que no considera por ejemplo a las mujeres o a quienes carecen de propiedad y está ubicado dentro de un espacio político pequeño y el segundo modelo ya tendría un ámbito mucho más universal y mucho más igualitario. Cfr David Held, Models of Democracy, Cambridge, Polity Press, 1987. Hay edición en español por Alianza Universidad.

14 Danilo Zolo, Democracy and Complexity, Cambridge, Polity Press, 1992, p. 66. 
fórmula democrática enemiga de cualquier procedimiento representativo, en el sentido de que la voluntad del pueblo no podía ser representada sino que debería estar siempre presente. Incluso, el ejercicio del poder tenía que ser expresado a través de un mandato imperativo y comisarial, el cual debería de gozar del consenso de todos pues a más consenso podía decirse que existía mayor democracia. ${ }^{15}$

Se trataba, en síntesis, de una tesis contraria a cualquier propuesta institucional - burocrática ya que Marx, por ejemplo, entendía por una auténtica democracia la supresión de cualquier estructura burocrática aboliendo así toda distinción entre poderes legislativos o ejecutivos, con lo cual toda acción de gobierno debía quedar bajo supervisión y control del pueblo. ${ }^{16}$ Evidentemente, no tardarían en aparecer críticas severas a esta definición de democracia sustantiva pues podía llevar anexada una visión política totalitaria y, más aún, revolucionaria que «se basaba en la creencia de la existencia de una sola verdad en la política. Esta podía ser llamada como un mesianismo político en el sentido que postulaba un esquema de cosas preordenado, armonioso y perfecto, hacia el cual se dirigían irremediablemente los hombres, y al que estaban confinados a llegar». ${ }^{17}$ Esta tendencia se vio reforzada desde el siglo XVIII con el pensamiento ilustrado y el racionalismo que consideraba que los hombres habían sido engañados por un esquema teológico que era completamente falso y que tales ideas debían superarse con una planificación adecuada fruto de la voluntad y la razón humana. ${ }^{18}$

En la práctica, lo que avizoraba la democracia sustantiva según el politólogo hebreo J. Talmon era la plasmación de una democracia totalitaria, esto es, de una dictadura que reposaba en el entusiasmo de los ciudadanos y mediante elementos cargados de ideología como la "voluntad general» se presentaba en realidad una nueva fe, un nuevo culto que terminaría por ahogar cualquier vestigio de libertad individual y de autonomía. ${ }^{19}$

15 Ibid

16 Ibid., p. 67.

17 J. L. Talmon, The Origins of Totalitarian Democracy, New York, Norton \& Company, 1970, p.2

18 Ibid., p. 3.

19 A pesar de que la democracia sustantiva buscase precisamente la salvaguarda de la verdadera libertad. Se trataría, sin embargo, de una forma de libertad positiva que entiende 
Pero, aparte de este matiz totalizante y arbitrario que presentaba la democracia sustantiva, también había quienes veían su poca o escasa viabilidad por otras razones que tenían que ver básicamente con lo abstracto e irreal de conceptos como voluntad general o bien común. De hecho, Joseph Schumpeter -quien representaba esta teoría- mencionaba que "no hay tal bien común, unívocamente determinado, en el que todo el mundo pueda estar de acuerdo o pueda hacérsela estar de acuerdo en virtud de una argumentación racional. Esto no se debe primordialmente al hecho de que algunos puedan querer cosas distintas del bien común, sino al hecho mucho más fundamental de que, para los distintos individuos y grupos, el bien común ha de significar necesariamente cosas diferentes". ${ }^{20}$ En este sentido, tampoco el concepto de voluntad general podía ser reivindicado como un concepto discernible por todos los individuos pues en principio no existía como ente real ya que lo que estaba detrás de él era simplemente una sumatoria de individuos particulares y distintos.

Finalmente, la vigencia de este tipo de democracia podía significar, en síntesis, la vigencia y dominio de las mayorías sobre las minorías quienes -las mayorías- usualmente respondían a emociones y a estímulos efímeros y particularmente volátiles. Este era entonces el comportamiento negativo de las multitudes como sentenciaba el clásico estudio del psicólogo francés Gustave Le Bon. ${ }^{21}$ Las muchedumbres, no podían ser racionales porque actuaban sin ningún fin u objetivo definido o unificado, y más bien podría decirse que representaban una voluntad irracional y voluble. Tales argumentaciones, coincidirían en el fondo con lo sustentado por Talmon, pues desembocarían irremediablemente en una ideología totalitaria y en grandes movimientos y partidos de masa que procurarían homogeneizar a todos bajo las banderas del partido. ${ }^{22}$

que la libertad se realiza en la búsqueda de un fin colectivo. J. L. Talmon, Ibid., p.2. Cf. también, Isaiah Berlin, "Two Concepts of Liberty» en Four Essays on Liberty, Oxford, Oxford University Press, 1969; John Gray, Liberalisms, London, Routledge \& Kegan Paul, 1989.

20 Joseph Schumpeter, Capitalismo, Socialismo y Democracia, Libro II, Cap. XXI, Barcelona: Orbis, 1983, p.322.

21 Citado por Joseph Schumpeter, Ibid., p.329.

22 Cfr. Francois Furet, The passing of an Illusion, the idea of communism in the twentieth century, Chicago, Chicago University Press, 1999. Existe edición en español por el Fondo de Cultura Económica. 
Así pues, resumiendo, esta primera tesis por acercarse al plano republicano (igualdad entre los ciudadanos) podía ser, como lo decía Schmitt, más política que ideológica. Sin embargo, el hecho de que Rousseau anclara su teoría dentro del concepto moderno de autonomía, hacía peligrar la estabilidad y viabilidad de esta propuesta. Esto ocasionaría que se alejase irremediablemente del plano político (real) para aproximarse al plano ideal de la igualdad universal, como lo sostenía la propuesta marxista y sus derivados. Del mismo modo, el crecimiento de las poblaciones, las migraciones, la expansión del capitalismo y la especialización laboral dificultarían la vigencia de la democracia sustantiva y podrían hacer realidad los temores expresados por Talmon y Schumpeter.

\section{Segunda teoría: la Democracia representativa}

Junto con la democracia sustantiva, la democracia representativa ocupa un amplio espacio en las discusiones tradicionales sobre la democracia, las mismas que usualmente llevan adelante políticos y abogados pues, a primera vista, aparecen como conceptos simples y deseables y estas características son particularmente útiles en los discursos efectuados a través de los medios de comunicación masivos.

Asimismo, la democracia representativa tendrá una gran afinidad con el liberalismo institucional cuya versión más difundida y lograda fue la de John Stuart Mill en el siglo XIX (que dicho sea de paso sentó las bases del Institucionalismo) y, por supuesto, con el Estado de Derecho y el positivismo que constituyen la fuente del Estado de Derecho o Constitucional. Por todas estas razones es que se hace necesario analizar con precisión los alcances de este modelo y obviamente sus debilidades comparando también sus semejanzas y diferencias con el modelo sustantivo.

Como mencionamos, Stuart Mill en su texto Consideraciones sobre el gobierno representativo ${ }^{23}$ representa lo que sería el nacimiento de una suerte de ingeniería constitucional, buscando las formas institucionales más óptimas para la configuración efectiva de un gobierno liberal

23 John Stuart Mill, Utilitarianism, Liberty and Representative Government, London, J. M Dent \& Sons Ltd, 1947. 
que garantice la libertad y la igualdad ${ }^{24}$. La idea del institucionalismo descansa entonces en el hecho de que se considera que las instituciones moldean la política, entendiendo por institución normas y procedimientos que dejan huella en los resultados políticos. En síntesis, «las instituciones influencian los resultados porque forman actores, identidades, poder y estrategias». ${ }^{25}$

Tal idea en realidad se había originado un poco antes, durante la Revolución Francesa, cuando en el recordado artículo dieciséis de la Declaración de los Derechos del Hombre y del Ciudadano de 1789 se mencionaba que una sociedad que carecía de derechos y que no establecía una división de poderes no tenía constitución. En otras palabras, los derechos individuales (libertad individual) y la división de poderes era la característica del sistema liberal democrático representativo.

Ahora bien, la división de poderes no sólo era inherente a la división del trabajo y los fines de eficacia que ella perseguía sino que se justificaba en función al viejo precepto liberal que se originó con John Locke y que nacía del peligro inminente de que seamos jueces de nuestra propia causa. ${ }^{26}$ Por último, se trataba de asegurar la libertad individual, frenar la arbitrariedad y hacer predecible las reglas que antes quedaban en manos de un soberano decisionista (absolutismo). ${ }^{27}$

Desde un comienzo, esta corriente de pensamiento político se opondrá entonces a cualquier forma de democracia sustantiva, pues iban a privilegiar la libertad sobre la igualdad, y si bien en un Estado libre cada quien debe ser su propio gobernante (lo cual es un rasgo de democracia sustantiva) no se debía de confundir la libertad con el poder. ${ }^{28}$ Hacer esto sería confundir el poder legislativo con el ejecutivo. Aún más, es obvio que la democracia sustantiva solo podría tener sentido dentro de pequeñas localidades que ya no existían y, asimismo, es también evidente que menos personas deciden más rápido y mejor que

24 R. Robert Putnam, Making Democracy Work, civic traditions in modern Italy, New Jersey, Princeton, Princeton University Press, 1993, p. 9.

25 Ibid., p.8.

26 John Locke, Two Treatises of Government, Cambridge, Cambridge University Press, 1988, Second Treatise of Government, Par. 87, 91.

27 Richard Bellamy, "The Political Form of the Constitution: the Separation of Powers, Rights and Representative Democracys en Constitutionalism in Transformation: European and Theoretical Perspectives, Blackwell, Oxford, 1996, ए. 26.

28 Ibid., p.33. 
un cúmulo de individuos que estarían todo el tiempo discutiendo. La democracia representativa traía entonces un control dentro del proceso democrático y procuraba elegir a los más capaces para ser los representantes pues, como decía Montesquieu, era mejor que la gente aceptara o rechazara candidatos antes que hiciera leyes. ${ }^{29}$

Pero volviendo a la visión de la división de poderes, había que asumir que esta perspectiva no solamente tenía que asumirse desde un punto de vista formal, sino también desde una posición sustantiva, pues la postura formal nos conduciría a conclusiones en las cuales se demostraría que la división formal de poderes es una falacia. ${ }^{30} \mathrm{Tal}$ posición sustantiva hablaría ahora de un requisito imprescindible y político que requeriría la democracia representativa: la "constitución mixta» que debería asegurar además que el poder político reflejase el balance natural de las diferentes clases sociales dentro del cuerpo político y proveyese los mecanismos para que se de un control mutuo. ${ }^{31} \mathrm{La}$ Constitución, la representación y lo que es más importante la división de poderes debía entonces ser un reflejo de la sociedad y de su variedad $y$, pluralismo pues no podría permitirse que una misma clase social acaparase todos los poderes. Sin embargo, esta constitución mixta que la vio viva todavía Montesquieu en Inglaterra -descrita en su famoso capítulo VI de su libro XI del Espíritu de las Leyes- y que también se podía apreciar en los Discursos de Maquiavelo, respondía a una realidad política orgánica y aun comunitaria pero que para fines del siglo XVIII e inicios del XIX ya no era posible que perdurase y por eso en El Federalista ${ }^{32}$ de Madison, Hamilton y Jay representa un primer intento por generar artificialmente una constitución mixta.

Sin embargo, dentro de esta democracia representativa se mantendrá siempre una tensión entre la parte sustantiva y la parte formal,

29 Citado por Richard Bellamy, Ibid.

30 Basta simplemente considerar que en el mundo político contingente la supuesta división de poderes entre el Ejecutivo, el Legislativo y el Judicial no se puede cumplir, pues un juez al momento de resolver un caso podría sentar un precedente jurisprudencial lo cual lo haría creador de una regla (legislador), o un funcionario público podría crear también legislación al momento de reglamentat una ley y, finalmente, el Parlamento al momento de interpretar una norma podría estar tomando el rol de la administración de justicia. Cfr Richard Bellamy, Ibid., p. 27.

31 Ibid., p. 29.

32 A. Hamilton, J. Madison, y J. Jay, The Federalist, London, Dent, 1992. 
entre la constitución mixta y la división del poder y, por ende, el propio intento de El Federalista indica también que la línea asumida será precisamente la de la «ingeniería constitucional", que tendría que basarse en la elección de procedimientos, técnicas y su aplicación, a fín de poder garantizar el pluralismo y que ninguna mayoría fuese capaz de imponerse sobre una minoría. En otras palabras, todo señalaría que va a ser la parte ideal y mecánica la que primará sobre la parte real y natural, y con ello la democracia representativa devendrá en una fórmula de democracia formal que busca de modo artificial generar un contenido. ${ }^{33}$

Quizá, uno de los mejores ejemplos de esta afirmación la podemos hallar en la ciencia política y la teoría democrática de Robert Dahl. Si la democracia sustantiva fallaba en parte por perseguir una igualdad cerrada que podría acabar con el individualismo y la autonomía, la democracia representativa pretendería, a su vez, garantizar la autonomía sin que esto sea óbice para producir un sistema desigual y arbitrario. En este sentido, sus objetivos podrían ser sintetizados en tres puntos centrales que se constituyeron en la tesis de Dahl, denominada Poliarquía. Para Dahl, la democracia debía de ser capaz de responder a las preferencias de todos los ciudadanos sin tener en cuenta su procedencia política y para hacer esto una democracia debía de asegurar en primer lugar la formulación de las preferencias ciudadanas, la posibilidad de expresar públicamente tanto entre sus partidarios como frente al gobierno tales preferencias y, por último, recibir igualdad de trato por parte del gobierno que implicase que no existiese ningún tipo de discriminación por dichas preferencias. ${ }^{34}$ Así pues, su propuesta busca-

33 De hecho hay una literatura abundante con respecto al modo como se concibe y desarrolla esta democracia formal o representativa. Ver por ejemplo Arend Lijphart, Democracy in Plural Societies, New Haven, Yale University Press, 1977, Arend Lijphart, Las Democracias Contemporáneas, Juan Linz y Arturo Valenzuela, La Crisis del Presidencialismo, Madrid, Alianza, 1997, Giovanni Sartori, Ingeniería Constitucional, México, FCE, 1994, Dieter Nohlen, Sistemas Electorales y Sistemas de Partidos, México, FCE, 1994, Guillermo O'Donnell, Contrapuntos, Buenos Aires, Paidós, 1997, Samuel Huntington, La Tercera Ola de la Democratización, Buenos Aires, Paidós, 1994, o Larry Diamond y Marc Plattner, The Global Resurgence of Democracy, Baltimore, The John Hopkins University, 1996.

34 Robert Dahl, La Poliarquía, participación y oposición, Madrid, Tecnos, 1989, publicada originalmente por Yale University Press, 1971. También del mismo autor se puede revisar A Preface to democratic Theory, Chicago, Chicago University Press, 1956; Who governs?, New Haven, Yale University Press, 1961, Democracy and Its critics, New Haven, Yale University Press, 1989 y más recientemente On Democracy, New Haven, Yale University Press, 1998. 
ba un punto medio entre la participación política y la posibilidad de expresar públicamente tales preferencias. De hecho, a lo largo de la historia de las instituciones políticas de occidente se había pasado de un modelo cerrado en el que no existía ninguna posibilidad de elegir ni de ser elegido -como era el caso de los primeros Estados modernos absolutistas (Dahl los denominaría hegemonías cerradas)- para luego mutar hacia modelos en donde o bien existía posibilidad de discutir públicamente aunque se daba una restricción para poder elegir (el caso de las oligarquías representativas tipo Suiza anteriormente) o, bien, si había una inmensa posibilidad de votar y elegir representantes pero no había ningún espacio para la discusión pública (las llamadas hegemonías representativas como fue el caso de la Unión Soviética). ${ }^{35}$ Más bien era en una democracia representativa -que él denominaría, como vimos, Poliarquía- donde se garantizaría la representación y la posibilidad de debatir públicamente, cumpliéndose así con las conocidas libertades civiles y políticas de todo sistema constitucional libera ${ }^{36}$.

Pero, lo que también hacía Dahl era mencionar que se debía generar un balance entre las fuerzas de mayoría y de oposición a fin de que a la mayoría le fuese mejor tolerar a la minoría, y esto se podía lograr a través de los incentivos económicos que serían finalmente quienes movilizarían la acción de los distintos grupos. ${ }^{37}$ Por ejemplo, según Dahl sería conveniente que la mayoría no tuviera tanto recursos que podrían ser usados para oprimir a la población, y que por eso le resultase más económico a la mayoría tolerar a las minorías.

Lo que proponía Dahl entonces, era una regulación de las conductas en torno al estímulo e impulso de las conductas políticas que se basaban en considerar a los actores políticos como sujetos racionales, que buscaban siempre maximizar sus recursos políticos. De todo esto podíamos formular algunas interrogantes: ¿Podía asumirse como real un escenario político en el cual se presupone que todos los actores se mueven en función a la racionalidad instrumental?, ¿bastan las reglas económicas para modificar las conductas y aproximarnos al ideal de la constitución mixta?, ¿¿existen evidencias que demuestren que la cons-

35 Robert Dahl, La Poliarquía, Ibid., pp.17-18.

36 Libertad de asociación, de expresión, de voto, para comperir por el voto, pluralidad información, elecciones libres e imparciales, etc., Ibid. p.15.

37 Ibid., p. 24 . 
titución mixta se da cuando se estructuran las reglas y crece la economía?

Tales preguntas difícilmente serán respondidas por la democracia representativa y por eso habrá que buscar las respuestas y nuevas preguntas en otras teorías.

\section{Tercera teoría: la democracia elitista y la democracia electoral}

En realidad existe una gama de teorias que coinciden en el hecho de que la democracia devendrá siempre en el gobierno de unos pocos sobre una gran mayoría, ora a través de la generación de una clase política o una élite de gobierno ${ }^{38}$ que dependan de su fuerza, inteligencia o carisma para imponerse, ora por medio una elección en la cual los candidatos compiten libremente para ganar el voto de los electores. ${ }^{39} \mathrm{La}$ primera recibe usualmente el nombre de democracia elitista, mientras que la segunda es la llamada democracia electoral. ${ }^{40}$ Sin embargo, ambas se distancian de sus antecesores (la democracia sustantiva y la representativa) en el sentido de que son más bien teorías descriptivas y realistas antes que prescriptivas, evaluativas o idealistas, lo cual las vincula más con la ciencia política, la sociología y la economía antes que con el derecho y la teoría política. Este realismo, entonces, proporciona una respuesta a la pregunta ¿qué es la democracia? Y puede derivar-como en el caso de Schumpeter- a un modelo formalista y minimalista en extremo, como veremos más adelante.

En cualquier caso, es importante resaltar el hecho de que esta perspectiva recupera la dinámica del poder y la diferencia -en algunos casos hasta diferencias políticas- que había sido subestimado por las teorías anterio-

38 Pensamos en Gaetano Mosca, La Clase Política, México, FCE, 1984; Max Weber, Economía y Sociedad, México, FCE, 1977; Robert Michels, Los partidos políticos, un estudio sociológico de las tendencias oligárquicas de la democracia moderna 2 Vols., Buenos Aires, Amorrortu, 1969; Wilfredo Pareto, Forma y Equilibrio Sociales, Oxford, Blackwell, 1976. También se puede ver, T.B. Bottomore, Minorías Selectas y Sociedad, Madrid, Gredos, 1966, J.H Meisel, El Mito de la Clase Gobernante: Gaetano Mosca y la élite, Buenos Aires, Amorrortu, 1975.

39 Joseph Schumpeter, Capitalismo, Socialismo y Democracia, Ibid.

40 Aunque David Held en su reconocido Models of Democracy, denomina como «elitismo competetitivo" a las tesis weberianas y a las fórmulas teóricas electorales de Joseph Schumpeter. Ibid. pp $143-185$. 
res, en especial por la democracia institucional o representativa, y puede convertir a la democracia en algo más cercano a un concepto político.

Como decía Mosca, no era difícil comprobar que en cualquier estructura política ha existido siempre una cabeza que se halla por encima de lo que el denominaba la clase política, pero que tal gobernante no podría serlo sin el sostén de esa clase dirigente. Es más, este gobernante nunca podría oponerse totalmente a la clase política a menos que se esté constituyendo una nueva clase. Pero, igualmente, si surgía un gran descontento dentro de la masa que llegara a destronar a esa clase política, inmediatamente irrumpiría otra en su reemplazo. ${ }^{41}$ Así pues, Mosca sabía que tesis como la rousseauniana, en la que la mayoría de las personas podía participar en el gobierno, eran una ilusión, y tuvo muy claro que una sola persona no puede gobernar a una masa pero una minoría sí puede imponerse a una mayoría. ${ }^{42}$

Y de aquí Mosca argüirá en el sentido de que «la fuerza de cualquier minoría es irresistible frente a cada individuo de la mayoría, que se encuentra solo ante la totalidad de la minoría organizada. Y, al mismo tiempo, se puede decir que ésta se halla organizada precisamente porque es minoría. Un ciento que actúen siempre concertadamente y en inteligencia los unos con los otros, triunfarán sobre mil tomados uno a uno y que no tengan acuerdos entre sí; y, al mismo tiempo, les será mucho más fácil a los primeros actuar concertadamente y tener de esta manera un entendimiento, si son cien y no mil.» ${ }^{43}$ Ahora bien, tal clase política se diferenciaba de la masa en la medida de que poseían ciertas cualidades que los destacaba y que posiblemente pudieron haber sido heredados. De hecho, en toda sociedad o cultura siempre existió una clase que se abocó a las tareas de gobierno, a la administración, la guerra, la religión y la moral y constituían un grupo minoritario.

Desde la sociología, por otro lado, ya se demostraba que cualquier organización social tenía que concluir estableciendo una oligarquía, al punto tal que se argumentaba en el sentido de que era inconcebible la democracia sin organización ${ }^{44} y$, a su vez, la organización tendrá que llevarnos a la oligarquía, como lo señalaba Michels: «En toda organi-

41 Gaetano Mosca, La Clase Política Ibid., pp.107 - 108.

42 Ibid., p. 109.

43 Ibid., p. 110.

44 Robert Michels, Los Partidos Políticos, Vol 1. Ibid., p. 67. 
zación, ya sea de partido político, de gremio profesional, $u$ otra asociación de ese tipo, se manifiesta la tendencia aristocrática con toda claridad. El mecanismo de la organización, al conferirle solidez de estructura, induce algunos cambios importantes en la masa organizada, e invierte completamente la posición respectiva de los conductores y los conducidos. Como consecuencia de la organización, todos los partidos o gremios profesionales llegan a dividirse en una minoría de directivos y una mayoría de dirigidos». ${ }^{45}$

Así pues, el mismo Robert Michels señalaría en 1911 que: «la organización es lo que da origen a la dominación de los elegidos sobre los electores, de los mandatarios sobre los mandantes, de los delegados sobre los delegadores. Quien dice organización dice oligarquía». ${ }^{46}$ Esto, que se conocía entonces como la ley de hierro de la oligarquía -que había sido establecida por Michels, pero que también podía ser aceptada por el sociólogo italiano Wilfredo Pareto-, establecía que en toda sociedad debía de existir siempre una minoría dirigente, o también llamada una clase política o una oligarquía gobernante.

De aquí podía derivarse una regla general, que establecería "que el aumento de poder de los líderes es directamente proporcional a la magnitud de la organización». 47 Toda organización política sea un partido, un sindicato etc., será siempre el resultado de una estructura burocrática desarrollada jerárquicamente pues de otro modo desaparecería la organización. Las masas, por su parte, como ya lo decía el mismo Mosca, estaban en incapacidad de tomar decisiones y requieren siempre de un liderazgo fuerte y, por ende, sus iniciativas de la masa nunca podrán ser tomadas como originarias sino que serán siempre los intereses de los líderes. ${ }^{48}$

Empero, no se trataba de un sistema que buscaba generar un ambiente cerrado, en el cual las oligarquías o las minorías mantuviesen un monopolio del poder que eternizara al grupo dominante. De hecho, junto a la ley de la oligarquía existía también la ley de la circulación de las élites o también denominada por Pareto circulación de las minorías selectas. Ciertamente, el mismo Pareto ya había hecho célebre la frase

45 Ibid., Pp.77-78.

46 Saymour Martin Lipset, Introducción a Los Partidos Políticos, Ibid., p.13.

47 Robert Michels, Ibid. p.78.

48 Seymour Martin Lipset, Introducción a Los Partidos Políticos, Ibid., PF. 15 - 16. 
de que «la historia es un cementerio de aristocracias», ${ }^{49}$ y esto daba pie para entender de que las llamadas oligarquías estaban en permanente movimiento y, por ende, se trataba no solo del reemplazo de una minoría por otra minoría sino también del cambio individual dentro del propio grupo dirigente, que podía recibir nuevos miembros y sacar a otros. $^{50}$ En este último caso, las minorías se robustecían con el aporte de las familias de las clases bajas. ${ }^{51}$

Por ejemplo, una de las discípulas de Pareto, Marie Kolabinska, llegó a precisar las diferentes alternativas de circulación que existían distinguiendo tres tipos de circulación: "está, en primer lugar, la circulación que tiene lugar, entre categorías diferentes de la misma minoría gobernante. En segundo lugar, se halla la circulación entre la minoría selecta y el resto de la población, que puede adoptar una de las dos formas: 1) individuos del estrato inferior pueden lograr la entrada en la minoría existente; o, 2) individuos de los estratos inferiores pueden formar nuevos grupos de minoría selecta, en cuyo caso éstos se empeñan en una lucha por el poder contra la minoría existentem. ${ }^{52}$

Sin embargo, pese a que Pareto y Kolabinska se esforzaban en mostrar que habían comprobaciones empíricas e históricas que demostraban que sí se producía realmente esta circulación -como por ejemplo, cuando Pareto señalaba que los trabajadores ingleses en la era industrial habían alcanzado a constituir una minoría selecta de sindicatos o que en el caso francés a lo largo de su historia se había visto florecer distintos grupos de burgueses, profesionales como abogados, economistas etc.-, los críticos de la democracia elitista que provenían básicamente de las canteras sociológicas marxistas, no estaban satisfechos con las justificaciones de los elitistas. ${ }^{53}$ Así, se podría decir que no existirían

49 T.B Bottomore, Minorías Selectas y Sociedad, Ibid. p. 60.

50 Ibid.

51 Ibid.

52 Ibid., pp.61 - 62.

53 No debemos olvidar también que Pareto fue un seguidor del libre mercado y sus soluciones óptimas, vale decir el responder a las mayores preferencias de toda la comunidad aunque esto obviamente sufriría el problema de las conocidas externalidades. Cfr. Richard Bellamy, Liberalism and Modern Society, Cambridge, Polity Press, 1992, p. 137.

Obviamente dentro del mercado no sería tampoco dable la circulación de las élites pues lo más probable es que quien inicia sus intercambios en el mercado con cierta cantidad al final se quede con lo mismo, lo cual significaría que las mismas élites que poseen más poder seguirían teniéndolo. 
evidencias históricas que demostrasen este aserto y que en realidad es difícil hablar de una gran movilidad social. "Las desigualdades más importantes que existen en la sociedad son principalmente productos sociales, creados y sostenidos por las instituciones de la propiedad y la herencia, por el poder político y militar, y apoyados por creencias y doctrinas determinadas, aun cuando no siempre se resistan a las ambiciones de individuos destacados"..$^{54}$

Pero, así como eran conocidas -y criticadas- las teorías elitistas, también podía incluirse junto a ellas las teorías electorales del economista austríaco Joseph Schumpeter, quien se hizo conocido por criticar lo que él denominaba la "teoría clásica de la democracia", ${ }^{55}$ que supuestamente consistía en el gobierno de $\operatorname{todos}^{56}$ (manifestado, por ejemplo, en el concepto rousseauniano de la voluntad general o de conceptos más antiguos como el del bien común y que también estaban siendo usadas por corrientes ideológicas como el marxismo y su propuesta de dictadura del proletariado). En este sentido, «la más radical versión de la doctrina clásica (que nos lleva de Rousseau a Babeuf y de allí a Marx, el sovietismo de Lenin, los consejos de trabajadores de Rosa Luxemburgo, el autogobierno de los productores en Gramsci y termina idealmente con la teoría marxista del fin del Estado), se completa con la amalgama entre las nociones de democracia, voluntad general y el bien común. $n^{57}$

Casi en una línea kantiana se podría decir también que la democracia clásica se realiza cuando la voluntad de los individuos, que es autónoma, coincidiría con la voluntad de la autoridad heterónoma y de esta manera se produciría la anhelada síntesis presente por ejemplo en el Reino de los Fines. ${ }^{58}$ Pero, el problema de fondo, era precisamente que tal cosa, esto es, el reino de los fines, la voluntad general, la dictadura del proletariado o el bien común no existían en realidad y que no

54 T.B Bottomore, Ibid., p.165.

55 J.A Schumpeter, Capitalismo, Socialismo y Democracia, Ibid., Cap. XXI "La filosofía de la democracia del siglo XVIII puede ser compendiada en la siguiente definición: el método democrático es aquel sistema institucional de gestación de las decisiones políticas que realiza el bien común dejando al pueblo decidir por sí mismo las cuestiones en litigio mediante la elección de los individuos que han de congregarse para llevar a cabo su voluntad". p.321.

56 Democracia sustantiva que se plasmaba en la identidad entre gobernante y gobernados.

57 Danilo Zolo, Complexity and Democratic Theory, Ibid., p.66.

58 Ibid. 
eran sino abstracciones efectuadas por filósofos e ideólogos, quienes levantaban una bandera que no tenía su correlato fáctico en el reino de la política. Sin embargo, podía legítimamente pensarse que estas abstracciones eran utilizadas por minorías para hacerse del poder y permanecer en él, aduciendo que representaban a todo el pueblo y encarnaban su voluntad. ${ }^{59}$

Así pues, Schumpeter empezaba a deconstruir el ideal de voluntad general al mencionar que las personas no sólo tienen múltiples deseos, sino que también tienen valores muy diferentes, casi nunca coinciden las personas en sus fines sino que incluso cuando lo hacen pueden tener distintas y contrapuestas razones para hacerlo. ${ }^{60}$ Esta característica, correspondía por cierto a la descripción de las sociedades industriales que constituían sociedades plurales y que poseían una infinidad de bienes que eran siempre materia de elección individual. Obviamente, esta perspectiva era compatible con una visión economicista y que partía del individualismo metodológico.

Pero, el problema no sólo tenía que ver con la abstracción de tales conceptos. Schumpeter podría esgrimir también que las decisiones de las autoridades no necesariamente democráticas serían usualmente mejor recibidas y aceptadas que las decisiones democráticas. Citaba para ello, el ejemplo del acuerdo religioso o concordato que logró Napoleón Bonaparte en Francia a inicios del siglo XIX, siendo un dictador pero teniendo el apoyo del pueblo. ${ }^{61}$ Por último, apelando a la naturaleza maleable y emotiva de la gran mayoría de personas, Schumpeter cuestionaba la autenticidad de la voluntad general como bien objetivo e identificable pues podía ser objeto de un sin fin de manipulaciones y transformaciones, usando los medios de comunicación que generaban distintos mensajes, los mismos que estimulaban constantemente las conductas individuales, ${ }^{62}$ la incertidumbre de la voluntad general y a fortiori la incertidumbre de las conductas individuales, todo lo cual hacía literalmente que la teoría clásica, en palabras de Schumpeter, se desmoronase inevitablemente y se convirtiera en polvo. ${ }^{63}$

59 Joseph Schumpeter, Ibid. pp. 325 - 326.

60 David Held, Models of Democracy, Ibid., p. 172.

61 Joseph Schumpeter, Ibid. p.327.

62 David Held, Ibid., p. 173.

63 Joseph Schumpeter, Ibid., p.324. 
Ante la debilidad de la teoría clásica, Schumpeter oponía entonces una nueva democracia que algunos denominarían neo-clásica ${ }^{64}$ y que podría definirse ya no en términos filosóficos abstractos sino, más bien, de modo político y concreto, esto es, que buscaría definir a la democracia tal y como es y no como debería ser. Siendo esto así, tendría que llegar a la conclusión de que la democracia es fundamentalmente un método político que se usa "para llegar a las decisiones políticas, en el que los individuos adquieren el poder de decidir por medio de una lucha de competencia por el voto del pueblom. ${ }^{65}$

Entonces, Schumpeter nos lleva, como se dice, a una suerte de mercado político en el que se competirá por los votos del pueblo, ${ }^{66} \mathrm{y}$ donde los políticos serán también una especie de empresarios dinámicos que buscarán el reconocimiento de su plan político a fin de que sean favorecidos con la aceptación del pueblo. ${ }^{67}$ La función del votante será pues la de aceptar o rechazar a un jefe o gobernante, el jefe será quien provea de las complejas decisiones políticas en tanto que el electorado brindará la legitimidad para la acción del gobernante. ${ }^{68}$ Se entendía así que era imprescindible para el funcionamiento de la democracia no solamente la libertad de expresión y la libertad de asociación, sino también el derecho de participar tanto como elector como también -y más importante aún- como candidato para poder alcanzar el poder. ${ }^{69}$

Pero, pese a las críticas que pudiesen hacerse a la tesis de Schumpeter y que iban dirigidas, por ejemplo, al formalismo de su visión que impedía la institucionalización, o al hecho de banalizar la política al hacer de ella un mero trámite para elegir gobernantes basándose en relaciones efímeras o que pudiesen ser proclives a la generación de regímenes dictatoriales -como cuando se quisiese desprender de un gobierno

64 Cfr. Danilo Zolo., Ibid. También Carole Pateman, Participation and Democratic Theory, Cambridge, Cambridge University Press, 1970.

65 Joseph Schumpeter, Ibid., p.343.

66 Esta fórmula schumpeteriana será muy influyente en lo que significa por ejemplo la teoría económica de la acción política o también llamada public choice. Ver por ejemplo el texto clásico de Anthony Downs, An Economic Theory of Democracy, edición en español, Madrid, Aguilar, 1973.

67 David Held, Ibid., p. 174.

68 Ibid., p.175.

69 Nótese aquí la relación de la tesis schumpeteriana con algunos de los postulados de la democracia representativa planteada por Robert Dahl y su Poliarquía. 
impopular y que, según las leyes del mercado, podría ser cambiado inmediatamente por un nuevo "producto " ${ }^{70}$ legitimando así un golpe de Estado-, quedaba también claro que la idea schumpeteriana buscaba elegir políticos honestos, capaces y que pudiesen manejar adecuadamente la compleja burocracia de las sociedades industriales. ${ }^{71}$ Asimismo, no podía tolerarse a aquellos grupos o personas que compitieran por el poder con el propósito de cerrar la competencia futura, a pesar de que este modelo era favorable tanto al reconocimiento de una realidad política ineludible como el pluralismo y también al hecho político más reconocido de la modernidad, como lo es el fenómeno del caudillaje. $^{72}$

Finalmente, pesarán más los argumentos que señalaban que las democracias elitistas y electorales estaban reñidas con la idea sustancial de la democracia, que es la igualdad; y esto producirá un retorno de inquietud igualitarista vía la denominada democracia deliberativa que pasaremos a analizar a continuación.

\section{Cuarta teoría: la democracia deliberativa}

Si la democracia institucional o representativa pecaba por estrecha y neutral (apolítica), en cuanto buscaba ser básicamente un mecanismo o procedimiento formal para elegir representantes (aunque es cierto que consideraba también un elemento valorativo, como sería el de la protección de la libertad individual empero entendida como elección individual), la democracia deliberativa -último desarrollo en la teoría democrática- se dirigía más bien a ensanchar sobremanera la base axiológica y, en este caso, no sólo abarcaba la libertad real sino también la igualdad concreta pero en un plano de síntesis casi perfecta. De hecho, la democracia deliberativa podía presumir que poseía las ventajas de todos los modelos anteriormente presentados y más bien prescindía del pasivo de cada una de ellas. Así, si la democracia sustantiva acotaba la libertad en aras de la igualdad y la democracia representativa

70 A fin de cuentas, dentro de esta analogía entre el mercado y la polis, el gobierno no es sino un producto más que puede ser fácilmente intercambiable.

71 David Held, Ibid., p.176.

72 Joseph Schumpeter, Ibid., p.345. 
recortaba la igualdad en favor de la libertad, la democracia deliberativa apuntaba a conciliar a ambas sin ninguna reducción.

De hecho, todas las teorías democráticas vistas parecían que no lograban respetar plenamente el principio liberal kantiano de la dignidad dentro del conocido imperativo categórico, esto es, de tratar a cada ser humano como fin en sí mismo y no como medio. Tanto las teorías elitistas y electorales de la democracia, por ejemplo, resaltaban el rol ineludible del poder dentro de la democracia y por ende la imposibilidad de cumplir con el principio de la dignidad. Asimismo, la democracia representativa se mimetizaba de maravilla con el mercado y éste generaba desigualdades manifiestas que tampoco le hacían mucho favor al precepto de la dignidad.

Si es entonces la idea de la justicia y la imparcialidad la que busca realizar la democracia, como habían sostenido, entre otros los padres fundadores de los Estados Unidos, la pregunta inevitable tenía que ser la de como era posible hallar tal imparcialidad. Y, fueron los mismos padres fundadores quienes afirmaron que la decisión imparcial debía ser fruto de una deliberación cuidadosa entre todos los representantes de la sociedad..$^{73}$ Ahondando un poco más en esta posición, podía decirse que frente a la "parcialidad ${ }^{74}$ de las decisiones políticas comunes, la deliberación permitiría conocer las preferencias de todas las partes. Del mismo modo, las personas podrían modificar sus argumentos para hacerlos aceptables a los demás pudiendo también corregir o mejorar sus posiciones y, por último, podría también educar a las personas para que actúen de manera imparcial. ${ }^{75}$

73 Roberto Gargarella, "Full Representation, Deliberation, and Impartiality", p.260, en Deliberative Democracy, editado por Jon Elster, Cambridge, Cambridge University Press, 1998. También, Carlos Santiago Nino, La constitución de la democracia deliberativa, Barcelona, Gedisa, 1997, Caps. 5 y 6.

74 Debido a la ignorancia de las preferencias o deseos de las personas. Por cierto, el término "parcial" es usado también por los teóricos de la democracia deliberativa. Cfr. Cass Sunstein, The Partial Constitution, Cambridge, Mass, Harvard University Press, 1993.

75 Roberto Gargarella, Ibid. p.261. También en Carole Pateman, Democratic Theory and Participation, Ibid; Benjamin Barber, Strong Democracy, Berkeley, University of California, 1984, J. Cohen "Deliberation and Democratic Legitimacy" en : A. Hamlin and P. Petit (eds.) The Good Polity: Normative Analysis of the State, Oxford, Oxford University Press, 1989 y Jon Elster, "The Market and the Forum" en: J. Bohman y W. Rehg, Deliberative Democracy,: Essays on Reason and Politics, Cambridge, MA: The MIT Press, 1997. 
Ciertamente, la idea de la comunicación y el diálogo no es nueva, ni en la política antigua, ni obviamente en la política contemporánea. Sin embargo, como veremos luego, el diálogo político contemporáneo distará mucho del antiguo. Quizá se pueda decir que el inicio de esta teoría deliberativa provenga de uno de los filósofos más populares de la modernidad, Immanuel Kant, quien en el célebre ensayo Qué cosa es la ilustración escribía: «la Ilustración es la salida del hombre de su culpable minoría de edad. Minoría de edad es la imposibilidad de servirse de su entendimiento sin la guía del otro. Esta imposibilidad es culpable cuando su causa no reside en la falta de entendimiento, sino de decisión y valor para servirse del suyo sin la guía de otro. ¡Sapere aude! ${ }_{\mathrm{i}}$ Ten valor de servirte de tu propio entendimiento! Tal es el lema de la Ilustración. ${ }^{76}$

Como se aprecia, lo esencial para Kant era la capacidad de juicio, la misma que reposaba en un acuerdo colectivo (universal). Se entablaba entonces una crítica a todas las instituciones políticas existentes hasta ese momento, que no habían tomado en serio a la razón humana y que ni siquiera pensaban que valía la pena escuchar públicamente las razones de «los otros». Ni la igualdad, ni la libertad podían manifestarse si es que no se generaba esta "República de los Fines» o espacio público que muy bien podría coincidir con una suerte de escenario ideal de comunicación y crítica, ${ }^{77}$ en el que cada individuo racional y libre (autónomo) contribuía para producir un ambiente de paz en el que se respetase las opiniones de todos a fin de construir una moral aceptable.

Esta misma idea de la paz vinculada al diálogo ya había sido expuesta también por otra conocida filósofa moderna, como Hannah Arendt, quien mediante la diferenciación entre la esfera pública y la esfera privada asociaba a la primera con la libertad y la igualdad, mientras que a la segunda con la necesidad y con la jerarquía. ${ }^{78}$ Lo más importante, sin embargo, era que el espacio público se caracterizaba por el diálogo como acontecía en las polis griegas y sus famosas asambleas. Ahora

76 Immanuel Kant, «Respuesta a la pregunta: ¿Qué es la Ilustración?» en En defensa de la ilustración, Madrid, Alba editorial, 1999, p. 63.

77 Como lo señalaría más contemporáneamente un filósofo alemán no muy lejos de la tradición kantiana, como lo es Jürgen Habermas, Ensayos Políticos, Barcelona: Península, 1988; y recientemente Facticidad y Validez, Madrid, Trotta, 1998.

78 Hannah Arendt, La Condición Humana, Barcelona, Paidós, 1993, pp. 42 - 45. 
bien, este diálogo se ligaba siempre con la paz, mientras que el plano jerárquico de la familia (mundo privado) se sostenía en el silencio y, por ende, podía generar violencia. ${ }^{79}$ La famosa isonomía de los griegos no solo implicaba que todos eran iguales ante la ley o que la ley sea la misma para todos, sino que todos tenían derecho a la actividad política y esta actividad política solamente era posible a través del hablar de unos con otros. ${ }^{80}$ En este sentido, Hannah Arendt creía que una condición importante para el funcionamiento de la deliberación en el mundo contemporáneo era la existencia de los prejuicios ya que a través de la discusión (política) se podían aclarar y disipar; de no existir entonces la deliberación, jamás podríamos salir de los prejuicios y con esto podíamos generar nuevamente violencia y arbitrariedad. ${ }^{81}$

De las tesis kantianas y arendtianas finalmente llegamos a Jürgen Habermas y su "racionalidad comunicativa» ${ }^{82}$, que era también un aporte fundamental para la conceptualización de la democracia deliberativa. Siguiendo una crítica a las tipologías de racionalidad propuesta por Weber, Habermas consideraba ${ }^{83}$ que la racionalidad típica de la Ilustración, esto es, la racionalidad instrumental, había servido para establecer una sociedad más bien desigual y violenta. En otras palabras, esta racionalidad reivindicaba el poder y por ende se oponía a los ideales centrales de la Ilustración, a saber, la igualdad y la libertad. En oposición a esto y empleando la racionalidad comunicativa, sugería una restricción del poder en aras de la comprensión y el respeto mutuo:

Que un hablante pueda impeler a un oyente a aceptar tal oferta, no se explica en función de la validez de lo dicho, sino de la

79 «Ser político, vivir en una polis, significaba que todo se decía por medio de palabras y de persuasión, y no con la fuerza y la violencian Ibid., p.40

Nosotros discutimos más profundamente este punto en Pensando Peligrosamente: el pensamiento reaccionario y los dilemas de la democracia deliberativa, Lima, Fondo Editorial de la Pontificia Universidad Católica del Perú, 1999.

80 Hannah Arendt ¿Qué es la Política?, Barcelona, Paidós, 1997, p.70.

81 Ibid., p. 50 .

82 Jürgen Habermas, La Teoría de la Acción Comunicativa, 2 Vols., Buenos Aires, Taurus, 1989, también Conciencia moral y acción comunicativa, Barcelona, Planeta, 1994.

$83 \mathrm{Y}$ aquí siguiendo el pensamiento de la teoría crítica elaborado por ejemplo en pensadores como Adorno o Horkheimer que mostraban su desilusión ante el proyecto de la ilustración. Cfr. T.Adorno y M. Horkheimer, Dialéctica de la Ilustración, Madrid, Trotta, 1998. 
garantía surgida de la coordinación que formula el hablante de que, llegado el caso, hará realidad la pretensión de validez que ha presentado. En el caso de pretensiones de verdad y rectitud, el hablante puede dar cumplimiento a su garantía por medios discursivos, esto es aduciendo razones; en el caso de pretensiones de sinceridad, mediante un comportamiento congruente (el hecho de que alguien piense de verdad lo que dice, es algo que solo puede demostrarse mediante la congruencia de sus actos y no acumulando motivos). En cuanto al oyente acepta la garantía ofrecida por el hablante, entran en funcionamiento aquellos vínculos relevantes a las consecuencias de la interacción que están contenidos en el significado de lo que se ha dicho. ${ }^{84}$

Tal tesis tenía entonces que desembocar en una teoría de la democracia deliberativa, en la que se fundamentara la institucionalidad mediante la discusión pública y la justificación de decisiones aunque, como lo decía también Habermas, no podía esperarse que esta perspectiva fuese un modelo para todas las instituciones sociales ${ }^{85}$ Sin embargo, podíamos imaginar algunas características de la democracia deliberativa, como lo mencionaba Joshua Cohen, quien estaba también muy próximo a Habermas. Entre otras cosas, la democracia deliberativa sostenía que el proceso de deliberación debía ser de una manera argumentativa, vale decir, por medio de un intercambio regulado de información y de razones; las deliberaciones tenían que ser inclusivas y públicas, ya que todos los afectados deben de formar parte de la discusión; la deliberación es libre de cualquier coerción exterior; del mismo modo también había que quedar libre de cualquier coerción

84 Jürgen Habermas, Conciencia moral y acción comunicativa, Ibid., p. 78.

85 Jürgen Habermas, Facticidad y Validez Ibid. Para este ensayo usamos la edición en inglés, Between Facts and Norms, Cambridge, Mass, The MIT Press, 1998, p. 305.

Habermas, en el fondo, al plantear ciertos límites formales a la deliberación lo hace simplemente para evitar caer en situaciones en las que la deliberación pueda poner en riesgo la validez de las instituciones democráticas, vale decir, del Estado de Derecho. Esta acotación la hacía al diferenciar su comprensión de lo que debía ser la democracia deliberativa de la propuesta de otro teórico de la democracia deliberativa como Joshua Cohen Cfr. "Deliberation and Democracy Legitimacy». Ibid. También del mismo Cohen se puede revisar "Democracy and Liberty» en: Deliberative Democracy, Jon Elster (edit.), Ibid., y "Procedure and Substance in Deliberative Democracy» en: Democracy and Difference: Changing Boundaries of the Political, de Seyla Benhabib (edit.), Princeton, NJ, Princeton University Press, 1996. 
interna que pudiese implicar, por ejemplo, un prejuicio hacia el otro interlocutor, todos tienen derecho de hablar pero también la obligación de escuchar, en este sentido, las conclusiones de $\mathrm{Si}$ o No deben motivarse solamente por la fuerza del mejor argumento; las deliberaciones en principio pueden ser indefinidas y reanudadas según sea decidido, empero, lo natural es que concluyan en una decisión, se entiende que en la práctica las mayorías pueden estar sosteniendo los argumentos más racionales a menos que la minoría convenza a la mayoría que ellas tienen la razón; las deliberaciones políticas se extienden a cualquier materia que pueda regularse para el interés de todos, podrían incluirse en todo caso asuntos que inicialmente fuesen definidos como privados $y$, por último, la deliberación política incluye la interpretación de necesidades y de deseos y el cambio de preferencias. ${ }^{86}$

En otra perspectiva también bastante difundida, ${ }^{87}$ teníamos una aproximación algo menos filosófica y más práctica que se basaba, en primer lugar, en el sentido de reciprocidad con el que debía de contar la democracia deliberativa para operar y esto quedaba expreso en su definición de democracia deliberativa:

La democracia deliberativa inquiere a los ciudadanos y funcionarios para que justifiquen públicamente sus políticas dando razones aceptables para los afectados por las medidas. Esta disposición implica tres principios -reciprocidad, publicidad y la responsabilidad ${ }^{88}$ [...] la reciprocidad es el principal principio porque le da significado a la publicidad y a la responsabilidad y también influye en la interpretación de la libertad oportunidad. ${ }^{89}$

Ciertamente, la reciprocidad era «la capacidad de buscar términos justos de cooperación por su propia causaw. ${ }^{90}$ En este sentido, la reciprocidad podía hallarse entre la imparcialidad y la prudencia (es decir en medio del altruismo y el interés personal) y se caracterizaba entre

86 Joshua Cohen, "Deliberation and Democracy Legitimacy» Ibid. Citado por Jürgen Habermas, Between Facts and Norms Ibid; pp. 305 - 306.

87 Nos referimos a la de Amy Gutmann y Dennis Thompson, en: Democracy and Disagreement, Cambridge, Mass, Harvard University Press, 1996.

88 El término real es accountability que resulta difícil de traducir al español

89 Amy Gutmann y Dennis Thompson, Ibid., p.52.

90 Ibid., p.53. 
otras cosas, por la aceptación mutua el deseo de justificarnos ante los otros, y una práctica de deliberación constituida por el acuerdo y el desacuerdo. ${ }^{91}$ El supuesto de la democracia deliberativa en el caso de Gutmann y Thompson era, entonces, el de contar con individuos razonables y racionales, los que por su lado racional intentasen satisfacer su interés personal, en tanto que por su lado razonable renunciasen a ciertas ventajas en aras de la convivencia y la paz social. En suma, la democracia deliberativa buscaba producir ciudadanos que fuesen al mismo tiempo ganadores y perdedores.

Hasta este punto, se podía tener una imagen bastante positiva en torno al sentido y los fines de la democracia deliberativa, y de ser cierto todo lo que describían sus defensores estaríamos sin hesitar ante un modelo muy superior ${ }^{22}$ a todos los analizados. Pero, a pesar de la novedad de la teoría deliberativa, más temprano de lo esperado aparecerían diversos argumentos que refutarían no solo la propia teoría deliberativa sino dudarían concretamente de la posibilidad de su aplicación.

Así pues, bastaba remitirse a la presencia del diálogo en la antigüedad para descubrir que el diálogo político por excelencia en el mundo de la democracia clásica era la oratoria ${ }^{93}$, y la oratoria tenía características muy concretas referente a su manejo y eficacia ${ }^{94}$. La oratoria requería de un auditorio extendido y plural, que debía ser persuadido para realizar determinada acción y esto implicaba que el contenido del discurso debía ser algo muy particular y concreto, que pudiese formar parte de la vida cotidiana de los ciudadanos. En este sentido, ellos recibían y refutaban el mensaje que en el fondo solamente buscaba producir la realización de un objetivo y, por ende, se podía sintetizar que el telos de la oratoria política era la decisión política. ${ }^{95}$

Pero, así como existía el diálogo político -oratoria- en la antigüedad también había espacio para otro tipo de diálogo (no político), y éste

91 Ibid.

92 Es superior en cuanto se adhiera uno a los fines que persigue la democracia liberal y que, como hemos sostenido, sería la síntesis entre la libertad y la igualdad.

93 Aristóteles, Retórica, Libro 1, Ciceron De Inventione, De Officis, De Oratore.

94 Todos estos argumentos se pueden encontrar en el excelente artículo de Gary Remer, "Political Oratory and Conversation, Cicero versus Deliberative Democracy", en Political Theory, Vol. 27, No 1, February 1999, pp. 39 - 64.

95 Ibid., p. 42. 
era la conversación. En el caso de la conversación, empero, existían diferencias sustantivas con respecto a la oratoria, pues, la conversación no buscaba persuadir, ni entretener sino reflexionar y buscar una verdad. Por lo tanto, la conversación tocaba más bien temas abstractos propios de la filosofía como la justicia, la felicidad, la libertad, etc. La conversación no funcionaba en auditorios sino más bien en cenáculos, que reunían a grupos de amigos y que ciertamente no sentían ni tenían la obligación de culminar la conversación, lo cual obviamente los facultaba a explayarse sin ninguna restricción. ${ }^{96}$

Ahora bien, si nos poníamos a comparar ambas formas de discurso con la teoría de la democracia deliberativa, encontrábamos que ella proponía un modelo de deliberación que no necesariamente tenía que ver con temas concretos (como la oratoria) sino que proponía también discusiones de tópicos relevantes para la comunidad que podían ser abstractos $^{97} \mathrm{y}$, claro está, esto ya representaba un grave problema pues al mismo tiempo la discusión política requería respuestas inmediatas, cosa que la deliberación sobre temas abstractos no podía satisfacer. Por otro lado, la discusión política clásica, la oratoria, siempre tenía elementos de jerarquía entre el orador y el auditorio; sin embargo, el discurso político de la democracia deliberativa proponía una comunicación entre iguales (como la conversación entre filósofos), algo que sólo podría ser real si es que las ciudades contemporáneas reunían a una colectividad de amigos. ${ }^{98}$

Así pues, la democracia deliberativa parecía estar condenada entonces a fracasar en tanto que confundía los contextos y los contenidos de los discursos, y esto se debía a la conexión que aun existía entre la democracia deliberativa y la filosofía liberal kantiana, que colocaba al sujeto moral en un plano trascendental y esto lo descontextualizaba. Se podía atestiguar tal afirmación cuando, por ejemplo, por más que existieran todos estos postulados teóricos de la democracia deliberativa, en

96 Ibid., p.45.

97 Como constituye la enorme cantidad de discusiones morales contemporáneas, como los debates sobre el aborto, sobre la libertad o la igualdad, sobre las corrientes feministas etc., y que hacen que los grandes temas políticos sean paradójicamente temas morales, y por ende abstractos.

98 Cosa que está absolutamente alejada de lo real en la medida de que las sociedades contemporáneas son demasiado plurales y culturalmente diferenciados para pensar en términos de comunidades de amigos. Cf. Jacques Derrida, Política de la Amistad, Madrid, Trotta, 1998. 
el fondo no todos los ciudadanos eran capaces de expresarse coherentemente o por más que lo hicieran siempre existirían minorías que no recibirían la misma atención al momento de exponer sus ideas en un auditorio. ${ }^{99}$ Entonces, si ninguna de las teorías democráticas lograban ser convincentes del todo, ¿̨habría que buscar alternativas de otra naturaleza?

\section{Quinta teoría: el modelo republicano y la democracia del futuro}

Cuando analizábamos las corrientes democráticas, desde las clásicas hasta las más novedosas, encontrábamos que en todos los casos -salvo la democracia sustantiva- se trataban de teorías que apostaban fundamentalmente por la libertad y el individualismo. En este sentido, podría decirse que au fond, estas teorías democráticas tenían que definirse como teorías liberales.

Ciertamente, las perspectivas individualistas siempre mantuvieron una relación difícil con la política que más bien tendía hacia lo colectivo antes que a lo individual. ${ }^{100}$ De hecho, un autor tan importante para la historia de la teoría democrática como Alexis de Tocqueville, comprobaba con preocupación en el siglo XIX cómo el individualismo empezaba a socavar una vida comunitaria, en la que los consejos locales y los pequeños comités permitían cultivar las virtudes democráticas al tiempo de fragmentar el poder. El temor de Tocqueville no necesariamente tenía que ver con la anarquía que esto producía, sino más bien con las nuevas formas de poder y dominación que surgiría con esta sociedad egoísta o sociedad comercial. ${ }^{101}$

Tal prognosis de Tocqueville sobre el sombrío futuro de la mayor democracia del planeta, sería confirmada en años recientes por diversos

99 Nosotros hemos profundizado esto en el capítulo $\mathrm{V}$ de nuestro libro, Pensando Peligrosamente: el pensamiento reaccionario y los dilemas de la democracia deliberativa. Ibid.

100 Como siempre lo mencionaba, por ejemplo, Carl Schmitt, destacando las incompatibilidades entre el liberalismo (individualismo) que era una ideología que generaba fuerzas centrífugas mientras que la democracia (homogeneidad), que era un concepto político, postulaba fuerzas centrípetas. Ver nuestro ensayo, «Carl Schmitt y los desafíos al Estado Constitucional» en: Pensamiento Constitucional, No.3, 1996.

101 Jean Bethke Elshtain, Democracy on Trial, New York, Basic Books, 1995, pp. 10 11. 
teóricos norteamericanos como Michael Walzer, ${ }^{102}$ Christopher Lasch ${ }^{103}$ y, especialmente, Michael Sandel. ${ }^{104}$ Así, por ejemplo, Walzer, en referencia a la sociedad americana -nuevamente paradigma de la democracia occidental- señalaría:

Nosotros somos quizá la sociedad más individualista que jamás existió en la historia humana. Comparada ciertamente con sociedades anteriores y con sociedades antiguas, todos estamos completamente liberados. Libres de seguir nuestro propio curso. Libres de planear nuestras vidas. Libres de elegir una carrera. De escoger un compañero o compañera y de cambiarlos. Libres de elegir una religión o no elegir ninguna. De elegir la política o la anti - política. Elegir un estilo de vida -sea cual fuere-. Libres de hacer lo que queramos, y esta libertad tan enérgica y excitante como es, es también profundamente desintegradora, haciendo muy difícil a los individuos el encontrar un soporte y una estabilidad comunal y también dificulta a cualquier comunidad el contar con la participación responsable de sus miembros individuales. Se lleva así al hombre solitario y a la mujer solitaria hacia el impacto de un común denominador bajísimo, la cultura comercial. Opera pues, contra todo compromiso hacia grandes uniones democráticas y también contra la solidaridad de todos los grupos culturales que constituyen nuestro multiculturalismom. ${ }^{105}$

Esta tesis que sintetiza las tendencias denominadas como comunitaristas y que se caracterizan entre otras cosas por anteponer la comunidad al individuo, el compromiso a la elección, la obligación al derecho, el altruismo al egoísmo, o el ciudadano al consumidor, han tratado de encontrar un significado distinto a las políticas democráticas contemporáneas que, como mencionamos, han estado bastante aleja-

102 Michael Walzer, Citizenship and Civil Society, Rutgers, New Jersey, New Jersey Committee for the Humanities Series on the Culture of Community, 1992.

103 Chistopher Lasch, The True and Only Heaven, New York: Norton, 1991.

104 Michael Sandel, Democracy's Discontent, America in search of a public philosophy, Cambridge, Mass, Harvard University Press, 1996.

105 Michael Walzer, Ibid., pp. 11 - 12. Citado por Bethke Elshtain, Ibid. pp. 11- 12. 
das de la política, al enfatizar un individualismo abstracto, que sustentado en una moral de derechos de base kantiana o en una moral utilitarista, ${ }^{106}$ han llegado a proponer como forma de vida un Estado neutral frente a los valores o lo que, en palabras de Sandel, sería una «República Procedimental». ${ }^{107}$

La República Procedimental refleja el ideal liberal - democrático de que nosotros somos «seres desencarnados», sujetos de derechos ${ }^{108}$ que elegimos nuestros bienes libremente sin interferencias de ningún tipo (por ejemplo, de los contextos sociales) y de hecho, que cada quien sabe lo que necesita, prefiere y desea. ${ }^{109}$ El Estado asume aquí un rol neutral frente a los valores pues, cada quien deberá decidir por sí mismo su plan de vida sin que el Estado o alguna persona decidiese por nosotros. La República Procedimental procura entonces crear un plano público en el que se coloquen en paréntesis la moral o la religión, ${ }^{110}$ haciendo entonces una distinción concreta entre la política y la filosofía. ${ }^{111}$

Ahora bien, como añadía Sandel: «la insistencia en que separemos nuestra identidad como ciudadanos de nuestra identidad como personas da lugar a un desafío obvio. ¿Por qué nuestras identidades políticas no deben reflejar nuestras convicciones morales o religiosas que afirmamos en nuestras vidas personales?, ¿por qué, al deliberar sobre la justicia y los derechos, debemos dejar a un lado los juicios morales que informan nuestra vida?m. ${ }^{112}$ Por cierto, este desprecio a la moral y la

106 Cfr. Michael Sandel, introducción al libro editado por él mismo, Liberalism and its critics, Oxford, Basil Blackwell, 1984.

107 Michael Sandel, Democracy's Discontent, Ibid.p.4. Aunque como el mismo Sandel comenta el término le fue sugerido por la teórica política Judith Shklar.

108 En el sentido kantiano, vale decir, que lo justo antecede al bien, o el derecho a la obligación.

109 Michael Sandel, Democracy's Discontent Ibid, p. 17.

Por cierto, tal aserto puede ser fácilmente contradicho o por lo menos evaluado con menos optimismo. Cfr. Jon Elster, Juicios Salomónicos, segunda reimpresión. Barcelona, Gedisa, 1999.

110 Ver por ejemplo de John Rawls, Political Liberalism, New York, Columbia University Press, 1993, Richard Rorty "The Priority of Democracy to Philosophy" en The Virginia Statute for Religious Freedom, edit. Merril D. Peterson y Robert C. Vaughan, Cambridge, Cambridge University Press, 1988, o Cass Sunstein, Legal Reasoning and Political Conflict, Oxford, Oxford University Press, 1996.

111 Michael Sandel, Democracy's Discontent, Ibid., p. 19.

112 Ibid., p. 18. 
religión se cuajó en el rechazo del pensamiento moderno y liberal a una moral o religión única, que sería finalmente la imposición de una creencia particular al resto de personas, pues el proyecto liberal partía siempre del supuesto de la inconmensurabilidad y pluralidad de las visiones morales.

$\mathrm{El}$ intento por poner en paréntesis nuestras convicciones morales como lo pedía el liberalismo neutral, sin embargo, estaba muy lejos de configurar una política neutral pues la vigencia de este liberalismo y las teorías democráticas que lo han acompañado a la larga demostraron que han servido solamente para introducir nuevos patrones de conducta moral, como lo ha corroborado acertadamente Sandel. Así, por ejemplo, el hecho de no pronunciarse sobre la licitud o no del aborto (como en el famoso caso Roe vs. Wade, donde la Corte argumentó que al no poder decidirse cuándo empieza la vida, entonces los no nacidos no pueden ser reconocidos por la ley como personas en el sentido completo del término) resolvieron a la larga permitir el aborto. En el fondo, entonces, la neutralidad solo encubriría una preferencia moral que sería la de favorecer el aborto y privilegiar de este modo la elección individual. ${ }^{113}$

Las tesis comunitaristas y republicanas como las de Sandel, apuntaban en el blanco cuando señalaban que el individualismo de la República Procedimental no alentaba la vida en comunidad y, que al contrario, más bien socavaba la unidad política al ubicar al derecho individual antecediendo a la idea del bien. Esta tesis del derecho que antecedía al bien era, sin duda, la tesis que habían aceptado mal que bien las democracias representativas, elitistas, electorales y deliberativas y aquí radicaba, entonces, la dificultad que tenían todas estas teorías para superar esta contradicción entre el sujeto de elección y la polís o, lo que cs lo mismo, entre la libertad y la igualdad. En este sentido, la teoría de la democracia sustantiva sí podía definirse como una teoría más política que las anteriores, en tanto que era la única de las teorías democráticas modernas que no aceptaba el privilegio del derecho sobre el bien, aunque tenía la dificultad de incorporar a la libertad y el pluralismo. 
Así pues, la tesis de la unidad entre la libertad individual y el concepto político de la igualdad tenía que ser descartada, pues en todas las teorías democráticas presentadas o bien se privilegiaba exclusivamente a la igualdad como lo era en el caso de las teorías democráticas sustantivas descartándose a la libertad individual, o bien se destacaba la libertad en desmedro de la igualdad política como ocurría con las democracias representativas, electorales, elitistas o deliberativas.

Ante tal aporía lo razonable sería evitar la polémica a nivel abstracto y dirigirnos al plano concreto que, como decía Aristóteles, siempre fue competencia del mundo político. Aquí pensaríamos, entonces, que la mejor manera de definir a la democracia sería a través de la virtud ciudadana, esto es, aceptar la fórmula clásica en la que el bien antecede al derecho -como en la democracia sustantiva- empero, sin llegar al igualitarismo extremo de esta perspectiva, esto podría hacerse al devolver a la sociedad su naturaleza corporativa u orgánica que implique entonces la presencia de una pluralidad de funciones dentro de la ciudad y que, a semejanza de los modelos clásicos, se puedan educar a los ciudadanos en la virtud de cada una de las funciones existentes hasta alcanzar el verdadero conocimiento político, lo cual significaría en el fondo la constitución de una aristocracia universal. ${ }^{114}$

¿Cual sería la vía para encontrar entonces la virtud política? Ciertamente, el único camino sería el de la educación liberal, ${ }^{115}$ que es la contraposición a la democracia de masas. ${ }^{116}$ Dicha cultura, como acertadamente afirmaba Leo Strauss, es aquella que puede ser apropiada de la manera más fácil y sin ningún esfuerzo moral o intelectual. Por ende, la democracia no podrá forjarse apelando a la cultura de masas sino a la educación, que forma caballeros dispuestos a comprometerse políticamente y a actuar responsablemente bajo parámetros de cooperación, teniendo como misión fundamental la de educar a otros a fin de que puedan transformase también en ciudadanos educados y dispuestos a

114 Leo Strauss, «What is Liberal education?» en Liberalism ancient and modern, Chicago, Chicago University Press, 1995, p. 4.

115 Debemos advertir que aquí el término educación liberal no tiene ninguna relación con el liberalismo individualista que estamos criticando, y que está presente en las teorías democráticas modernas, sino que apela a la noción de un hombre virtuoso.

116 Leo Strauss, Ibid., p. 5. 
realizar fines decentes. ${ }^{17}$ Sin la búsqueda de la virtud y la excelencia humana cualquier intento por realizar la síntesis entre la libertad y la igualdad quedará, entonces, completamente descartado. 